\title{
Characteristics of methane emission from wetland rice-duck complex ecosystem
}

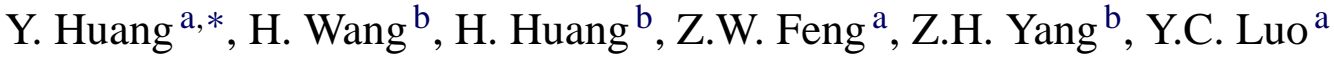 \\ ${ }^{a}$ Key Laboratory of Systems Ecology, Research Center for Eco-Environmental Sciences, Chinese Academy of Sciences, \\ P.O. Box 2871, Beijing 100085, PR China \\ ${ }^{\mathrm{b}}$ College of Agronomy, Hunan Agricultural University, Changsha 410128, Hunan Province, PR China
}

Received 13 December 2002; received in revised form 29 March 2004; accepted 5 April 2004

\begin{abstract}
The effects of rice-duck complex ecosystem on methane emission were investigated through two experimental approaches of plot and field experiments in subtropical region of China. Compared with conventional rice fields, the rice-duck ecological planting and breeding model significantly decreased the methane emission from paddy fields. Methane emission flux from rice-duck complex ecosystem presented distinct diurnal and seasonal variations. The diurnal variation in methane emission flux was basically consistent with daily temperature change, and methane emission flux reached a peak from 12 noon to 2 p.m. But the seasonal variation patterns of methane emission flux were not completely consistent between early rice and late rice. The peak of methane emission flux for early rice and late rice, respectively, appeared in the young panicle differentiation stage and the full tillering stage. Moreover, the seasonal fluctuation range of methane emission flux from early rice was smaller than that from late rice, and the total amount of methane emission from late rice also significantly higher than that from early rice. These results clearly indicate the possibility of reducing methane emission under wetland rice-duck complex ecosystem.

(C) 2004 Elsevier B.V. All rights reserved.
\end{abstract}

Keywords: Wetland; Rice-duck complex ecosystem; Methane emission flux; Rice; Oryza sativa

\section{Introduction}

Methane is one of the important greenhouse gases in the atmosphere, with about 25 times more infrared absorption capacity per molecule than $\mathrm{CO}_{2}$ (Rath et al., 1999). The increase in methane concentration in the atmosphere during the past decades has already aroused increasing concern throughout the world. Wetland rice agriculture is a major anthropogenic source of atmospheric methane (Conrad and Rothfuss, 1991; Conrad,

\footnotetext{
* Corresponding author. Tel.: +86-10-62849184/62923513; fax: +86-10-62923513.

E-mail address: huangcosmos@163.com (Y. Huang).
}

1996; Hanson and Hanson, 1996; Kumaraswamy et al., 2000), and this source has increased in recent years due to the expansion of rice cultivation (Singh and Singh, 1995). The amount of methane emission from wetland paddy fields accounts for 10-20\% of total methane emission, amounting to $50-100 \mathrm{Tg}$ year $^{-1}$ (Sass et al., 1994; Reiner and Milkha, 2000). It is projected that the methane emission from rice cultivation may increase to $145 \mathrm{Tg}_{\mathrm{gear}}{ }^{-1}$ in 2025 (Anastasi et al., 1992).

Methane emission from paddy fields is the net effect of methane production by methanogens and oxidation by methanotrophs eventually to carbon dioxide (Mishra et al., 1997; Watanabe et al., 1997). 
Table 1

Economic benefit under different utilization models (Wang et al., 2003)

\begin{tabular}{|c|c|c|c|c|c|c|c|}
\hline & \multicolumn{3}{|c|}{ Output value $\left(\text { yuan } \mathrm{hm}^{-2}\right)^{\mathrm{a}}$} & \multirow{2}{*}{$\begin{array}{l}\text { Duckling and its breeding } \\
\text { costs }\left(\text { yuan } \mathrm{hm}^{-2} \text { ) }\right.\end{array}$} & \multirow{2}{*}{$\begin{array}{l}\text { Nylon net cost } \\
\text { (yuan } \mathrm{hm}^{-2} \text { ) }\end{array}$} & \multirow{2}{*}{ 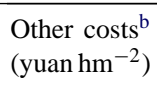 } & \multirow{2}{*}{ 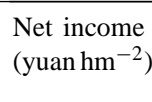 } \\
\hline & Rice & Adult duck & Duck egg & & & & \\
\hline $\mathrm{RFD}^{\mathrm{c}}$ & 5580.9 & 2916.0 & 2980.0 & 1653.0 & 259.5 & 2332.5 & 7231.9 \\
\hline $\mathrm{RMD}^{\mathrm{c}}$ & 5537.7 & 2808.0 & - & 1188.0 & 259.5 & 2332.5 & 4565.7 \\
\hline $\mathrm{PND}^{\mathrm{c}}$ & 5396.0 & - & - & - & - & 2587.5 & 2808.5 \\
\hline $\mathrm{NPND}^{\mathrm{c}}$ & 4066.2 & - & - & - & - & 2253.0 & 1813.2 \\
\hline
\end{tabular}

${ }^{a}$ Output value of rice yield, adult duck and duck egg converted at the price of $0.9,9.0,5.0$ yuan $\mathrm{kg}^{-1}$ respectively, and yuan is a unit of Chinese RMB.

${ }^{\mathrm{b}}$ Manpower input is not reckoned as input cost in this table.

${ }^{c}$ RFD, rice-female duck complex ecosystem (no application of pesticides and herbicides); RMD, rice-male duck complex ecosystem (no application of pesticides and herbicides); PND, paddy fields treated with applying pesticides and herbicides without raising duck; NPND, paddy fields treated with neither spraying pesticides and herbicides nor raising duck.

Under strictly anaerobic conditions of paddy fields, methanogens, a type of anaerobic organism, can transform a part of soil organic matter into methane (two main methane production routes: (1) $\mathrm{CH}_{3} \mathrm{COOH} \rightarrow$ $\mathrm{CH}_{4}+\mathrm{CO}_{2}$; (2) $\mathrm{CO}_{2}+4 \mathrm{H}_{2} \rightarrow \mathrm{CH}_{4}+2 \mathrm{H}_{2} \mathrm{O}$ ) (Takai, 1970; Wang et al., 1998). At the same time, methane can also be oxidized by methanotrophs that settled in the rhizosphere of rice plants and at the surface of flooded rice soils (Kumaraswamy et al., 2000). Transport through rice plants, diffusion and ebullition serve as three vehicles for transport of methane from the sites of production in the soil to the atmosphere (Wassmann et al., 1993). Therefore, the entire process of methane emission from rice fields, including production, oxidation and transport to the atmosphere is affected by biotic and abiotic factors, such as growth status of rice, temperature, soil characteristics (Conrad and Rothfuss, 1991; Masscheleyn et al., 1993; Neue, 1993; Sass et al., 1994; Yang et al., 1994; Denier et al., 1996; Hanson and Hanson, 1996; Yang and Chang, 1997, 1998; Rath et al., 1999; Kumaraswamy et al., 2000). In addition, under dif- ferent exploitation methods, the amounts of methane emission from wetland ecosystem are also different, usually varying from 0.47 to $171.12 \mathrm{mg} \mathrm{m}^{-2} \mathrm{~h}^{-1}$ (Wei, 2000). These results have provided important scientific basis for stipulating measures to reduce methane emission. Some research workers have also suggested probable mitigation options, but most of them are location-specific, which is a major constraint for their universal adaptation to diverse rice field conditions (Kumaraswamy et al., 2000). Hogan et al. (1991) suggest that the best mitigation approach would be to identify suitable and economically viable management practices for different methane emission sources and socioeconomic situations.

Wetland rice-duck complex ecosystem, as a type of integrated utilization method of paddy fields, has a long history, and is also a major complex planting and breeding model of paddy fields in South China. Our previous research work and other's research concerned have investigated and demonstrated that this model is a favorable integrated utilization method with relatively high economic benefits (Table 1) and

Table 2

Weed plant number and its fresh weight under different utilization models (mean values of six sampling occasions)

\begin{tabular}{|c|c|c|c|c|c|c|c|}
\hline & $\begin{array}{l}\text { Nutgrass }^{\mathrm{a}} \\
\text { (plant number } \\
\mathrm{m}^{-2} \text { ) }\end{array}$ & $\begin{array}{l}\text { Lakegrass }^{\mathrm{a}} \\
\text { (plant number } \\
\mathrm{m}^{-2} \text { ) } \\
\end{array}$ & $\begin{array}{l}\text { Pickerer } \\
\text { weed }^{\mathrm{a}} \text { (plant } \\
\text { number } \mathrm{m}^{-2} \text { ) }\end{array}$ & $\begin{array}{l}\text { Dwarfold world } \\
\text { arrowhead }^{\mathrm{a}} \text { (plant } \\
\text { number } \mathrm{m}^{-2} \text { ) }\end{array}$ & $\begin{array}{l}\text { Duckweed }{ }^{\mathrm{a}} \text { and } \\
\text { others }(\text { plant } \\
\text { number } \mathrm{m}^{-2} \text { ) }\end{array}$ & $\begin{array}{l}\text { Total plant } \\
\text { number (plant } \\
\text { number } \mathrm{m}^{-2} \text { ) }\end{array}$ & $\begin{array}{l}\text { Total fresh } \\
\text { weight } \\
\left(\mathrm{g} \mathrm{m}^{-2}\right) \\
\end{array}$ \\
\hline$\overline{R D^{b}}$ & 0.6 & 0.3 & 0.2 & 1.0 & 0 & 2.1 & 40.2 \\
\hline $\mathrm{CK}^{\mathrm{b}}$ & 2.3 & 2.0 & 2.2 & 4.7 & 5.4 & 16.6 & 231.6 \\
\hline
\end{tabular}

${ }^{\text {a }}$ Latin names for weed species are as follows: nutgrass (Cyperaceae), lakegrass (Echinochloa frumentacea (Roxb.) L.), pickerer weed (M. vaginalis (Burm.f.) Presl ex Kunth), dwarfold world arrowheadand (Sagittaria pygmaea Miq.) and duckweed (Lemna minor L.).

${ }^{\mathrm{b}} \mathrm{RD}$, rice-female duck complex ecosystem; CK, conventional rice field. 
Table 3

Rice disease and insect pest under different utilization models (mean values of six sampling occasions)

\begin{tabular}{llllll}
\hline & $\begin{array}{l}\text { Rice skipper } \\
\left(\text { number } m^{-2}\right)\end{array}$ & $\begin{array}{l}\text { Rice planthopper } \\
\left(\text { number } \mathrm{m}^{-2}\right)\end{array}$ & $\begin{array}{l}\text { Rice borer }^{\mathrm{a}} \\
\left(\text { number } \mathrm{m}^{-2}\right)\end{array}$ & $\begin{array}{l}\text { Incidence index } \\
\text { of rice blight }(\%)\end{array}$ & $\begin{array}{l}\text { Incidence index } \\
\text { of rice blast }(\%)\end{array}$ \\
\hline $\mathrm{RD}^{\mathrm{b}}$ & 0 & 8.7 & 0 & 1.9 & 1.7 \\
$\mathrm{CK}^{\mathrm{b}}$ & 0.5 & 43.2 & 0.4 & 11.2 & 8.3 \\
\hline
\end{tabular}

${ }^{\mathrm{a}}$ Latin names for weed species are as follows: rice skipper (Pelopidas mathias (Fabricius)), rice planthopper (Sogatella furcifera (Horvath)) and rice borer (Chilo suppressalis).

${ }^{\mathrm{b}} \mathrm{RD}$, rice-female duck complex ecosystem; CK, conventional rice field.

preferable ecological benefits (Ekurem and Ryohei, 1996; Zheng et al., 1997; Wang, 2000; Wang and Huang, 2002; Wang et al., 2003), including the decreasing and controlling effects of rice diseases and insect pests and weeds (Tables 2 and 3) as well as the melioration of soil physicochemical properties (Table 4). Wang (2000) observed and investigated the dissolved oxygen concentration of water body in rice-duck complex ecosystem, and found the dissolved oxygen concentration in the upper soil layer $(20 \mathrm{~cm}$ depth) of swimming lanes of ducks was $12.02 \mathrm{mg} \mathrm{l}^{-1}$, compared with the conventional paddy fields, increased $8.88 \mathrm{mgl}^{-1}$. Similar research result has also been reported by Zheng et al. (1997). It is predicted that the amount of methane emission may decline with the increased dissolved oxygen concentration in water body (Kumaraswamy et al., 2000). However, so far this ecological planting and breeding model effects on methane emission have not been investigated. Therefore, the main objectives of this study were:

(1) to evaluate the potential impact of wetland rice-duck complex ecosystem on methane emission from paddy fields;

(2) at the same time, to obtain information on the characterization (diurnal and seasonal variations) and quantification of methane emission from this complex ecosystem.

\section{Materials and methods}

\subsection{Site description}

The experimental site was situated at the experimental farm of Hunan Agricultural University, Hunan Province, South China, and located at $28^{\circ} 15^{\prime} \mathrm{N}$ latitude and $113^{\circ} 02^{\prime} \mathrm{E}$ longitude at an altitude of about $35 \mathrm{~m}$ above mean sea level. The experiments were carried out from July 2000 to October 2001.

This region has a humid mid-subtropical monsoon climate with an average annual air temperature of $16-18^{\circ} \mathrm{C}$, a mean annual precipitation of $1200-1700 \mathrm{~mm}$, most of the rain falling between April and August, and a frost-free period of 260-310 days. The soil of experimental sites is reddish-yellow paddy soil that develops from Quarternary red clay, with a relatively high soil fertility and convenient irrigation condition.

\subsection{Materials}

A double-rice cropping system of farming is commonly practiced in absolute most region of Hunan Province. Rice varieties for late rice in 2000 and for early rice and late rice in 2001 were Xiangwanxian No. 8, Xiangzhaoxian No. 31 and Weiyou 64, respectively, which are predominant local rice varieties and pro-

Table 4

Soil physicochemical properties under different utilization models

\begin{tabular}{lllllllllrr}
\hline & $\begin{array}{l}\mathrm{OM} \\
\left(\mathrm{g} \mathrm{kg}^{-1}\right)\end{array}$ & $\begin{array}{l}\text { Total N } \\
\left(\mathrm{g} \mathrm{kg}^{-1}\right)\end{array}$ & $\begin{array}{l}\text { Alkali N } \\
\left(\mathrm{mg} \mathrm{kg}^{-1}\right)\end{array}$ & $\begin{array}{l}\text { Available P } \\
\left(\mathrm{mg} \mathrm{kg}^{-1}\right)\end{array}$ & $\begin{array}{l}\text { Available K } \\
\left(\mathrm{mg} \mathrm{kg}^{-1}\right)\end{array}$ & $\begin{array}{l}\text { Bulk density } \\
\left(\mathrm{g} \mathrm{cm}^{-3}\right)\end{array}$ & $A_{1}{ }^{\mathrm{a}}(\%)$ & $A_{2}{ }^{\mathrm{a}}(\%)$ & $\mathrm{DC}^{\mathrm{a}}(\%)$ & $\mathrm{SC}^{\mathrm{a}}(\%)$ \\
\hline $\mathrm{Rd}^{\mathrm{b}}$ & 32.04 & 2.04 & 198.54 & 68.69 & 131.46 & 0.926 & 19.36 & 1.38 & 5.36 & 94.64 \\
$\mathrm{Ck}^{\mathrm{b}}$ & 30.46 & 1.90 & 181.23 & 66.16 & 103.24 & 0.936 & 16.71 & 3.13 & 11.99 & 88.01 \\
\hline
\end{tabular}

\footnotetext{
${ }^{a} A_{1}>0.25 \mathrm{~mm}$ soil aggregate; $A_{2}<0.001 \mathrm{~mm}$ soil aggregate; DC, soil dispersion coefficient; SC, soil structure coefficient.
}

${ }^{\mathrm{b}} \mathrm{RD}$, rice-female duck complex ecosystem; CK, conventional rice field. 
vided by the Rice Research Institute of Hunan Agricultural University. Fertilizers were applied at the standard rate of $300 \mathrm{~kg} \mathrm{~N}, 150 \mathrm{~kg} \mathrm{P}, 180 \mathrm{~kg} P$ per hectare.

Duck variety was Jiangnan No. 1 (provided by the Stock Farm of Changsha County, Hunan Province).

\subsection{Experimental design}

Paddy fields with ducks reared in them, viz. Wetland rice-duck complex ecosystem (RD), and conventional rice fields (CK) were used for two experimental treatments in this study. Neither chemical pesticides nor herbicides were applied throughout the growth period of rice in rice-duck complex ecosystem (RD), and a standing water depth of about $5 \mathrm{~cm}$ in these experimental paddy fields was maintained during the period of raising ducks. All management and agronomic practices were conducted as usual for the conventional paddy fields $(\mathrm{CK})$, including chemical pesticides and herbicides application.

Two experimental approaches, viz. the plot (PE) and the field experiment (FE), were synchronously carried out in this study with the intention of laying a forceful scientific foundation for the large-scale extension of this rice-duck planting and breeding model. The area of each plot in plot experiment was $66.7 \mathrm{~m}^{2}$. Six paddy fields with approximately equal area of $667 \mathrm{~m}^{2}$ were selected for the field experiment. Both the plot and the field experiments followed a completely randomized design with three replicates. All treatments in this study include RD and CK in the plot experiment, and $\mathrm{RD}$ and $\mathrm{CK}$ in the field experiment, abbreviating them to TPE, UPE, TFE and UFE, respectively.

At the beginning of the full tillering stage of rice, according to the standard of 300 ducks per ha, 15-day-old ducklings were introduced into the paddy fields (TPE and TFE). These paddy fields surrounded with nylon net $(50 \mathrm{~cm}$ in height) and a shed for the ducks was also built in the corner of each field. Feedstuffs were fed as usual for the ducks. These ducks were retrieved and transferred into other places to continue to be raised after the complete heading stage of rice in the experiments.

\subsection{Methane sampling and measurements}

Methane emission measurements were undertaken from the initial tilling stage to the ripening stage of rice. Gas samples were collected every $2 \mathrm{~h}$ between 8 a.m. and 6 p.m. at intervals of 3 days, adopting the closed chamber technique (Sass et al., 1990; Adhya et al., 1994; Mishra et al., 1997). The closed chambers $(10 \mathrm{~cm} \times 10 \mathrm{~cm}, 60 \mathrm{~cm}$ in height $)$ were made of Perspex sheet and the joints were sealed with silicone grease to make them leak proof. The chambers were placed over the aluminum alloy jackets $(10 \mathrm{~cm} \times 10 \mathrm{~cm} \times 10 \mathrm{~cm}$, with a water channel $1 \mathrm{~cm}$ wide to accommodate the chambers) and preinserted into the soil to a depth of $5 \mathrm{~cm}$ in advance (1 day before sampling) to ensure a minimum disturbance to the soil at the time of gas collection in the chambers. The water seal surrounding the chamber in the channel made the system airtight. Gas samples from the sampling sites of the experimental rice fields were drawn at 0-, 10-, 20- and 30-min intervals after installation of the chamber using an airtight syringe (capacity $20 \mathrm{ml}$ ). Then a slightly higher sample volume of gas (about $15 \mathrm{ml}$ ) was transferred into a evacuated vacuum container (capacity $12.5 \mathrm{ml}$ ) closed with an airtight rubber stopper by hypodermic needle to maintain a higher pressure than the atmosphere to avoid contamination or dilution of the collected gas sample. Mixing of the gas inside the chamber was accomplished at the time of sampling by drawing air out of the chamber headspace into a syringe and releasing it back into the chamber (about 10 times) before the final gas sample was withdrawn. The gas samples were analyzed by gas chromatography equipped with a flame ionization detector. The concentration of methane in a sample was determined by calculation using a standard curve obtained by injecting standard gas mixtures containing a known concentration of methane. The methane emission flux was calculated from the difference in methane concentration according to the equation of Parashar et al. (1993) and Singh et al. (1996):

$f=\left(\frac{V}{A}\right)\left(\frac{\Delta C}{\Delta t}\right)$

where $f$ is the methane emission flux $\left(\mathrm{mg} \mathrm{m}^{-2} \mathrm{~h}^{-1}\right)$, $V$ the volume of chamber above the soil $\left(\mathrm{m}^{3}\right), A$ the cross-section of chamber $\left(\mathrm{m}^{2}\right), \Delta C$ the concentration difference between zero and $t$ times $\left(\mathrm{mg} \mathrm{m}^{-3}\right)$ and $\Delta t$ the time duration between the two sampling periods (h). The amount of methane emission was determined by calculation, adopting the method described by Cai 
et al. (1998) and Lin et al. (2000). The total amount of methane emission was calculated from the summation of methane emission in several growth stages of rice. The soil temperature was measured with a soil thermometer under $10 \mathrm{~cm}$ depth of topsoil on the same day of gas sampling.

\subsection{Statistical analysis of data}

Data were analyzed by SAS software (version 6.12). Duncan's multiple range test and least significant difference tests were used where significant differences occurred.

\section{Results}

\subsection{Diurnal variations in methane emission from rice-duck complex ecosystem}

The courses of diurnal variations in methane emission flux from RD are given in Fig. 1. Though there were a bit of differences in methane emission flux in different growth stages of rice, the general variation trend of methane emission flux followed a similar pattern. The diurnal variations of methane emission flux basically coincided with daily temperature change. When the temperature was relatively low in the early morning, the methane emission flux was also relatively low, but with the increase of temperature during the hours before noon, the methane emission flux climbed gradually. From 12 noon to 2 p.m., methane emission flux reached a peak, thereafter declined gradually.

Before the ducks were introduced into the rice fields, viz. during the initial tillering stage of rice, the situations of methane emission flux between RD and CK were basically consistent (Fig. 1a) and there were no clear differences between them $(P>0.05)$. After the ducks were introduced into the rice fields, the situations were completely changed and the methane emission fluxes from RD were highly significantly lower than those from CK $(P<0.01)$, but the decrease rates vary with different periods of time within a day (Fig. 1b-e). After the complete heading stage of rice, ducks were retrieved and transferred into other places to continue to be raised. As can be seen from
Fig. 1f, no clear differences in methane emission fluxes between RD and $\mathrm{CK}$ were observed during the ripening stage of rice $(P>0.05)$. Fig. 1 also shows that the methane emission fluxes from the treatments in PE were lower than those from their corresponding treatments in FE.

\subsection{Seasonal variations in methane emission from early rice-duck complex ecosystem}

Seasonal variations in methane emission fluxes from early rice fields are presented in Fig. 2. The methane emission flux during the initial tillering stage of rice was kept at a relatively high level. But during the full tillering stage of rice, except for UFE, the methane emission fluxes from the other treatments (TPE, TFE and UFE) were slightly lower than those during the initial tillering stage. In addition, with the exception of UPE, the peaks of methane emission fluxes from the other treatments (TPE, TFE and UFE) all appeared in the young panicle differentiation stage. Thereafter, the methane emission fluxes declined gradually, and presented a minimal value during the complete heading stage, and then again increased to a varying degree during the ripening stage of rice.

\subsection{Seasonal variations in methane emission from late rice-duck complex ecosystem}

Fig. 2 gives the seasonal variations in methane emission fluxes from late rice fields. The methane emission varied considerably during the growth period of rice plant, and the seasonal fluctuation range of methane emission flux from late rice was greater than that from early rice, which can also be seen from their respective seasonal coefficients of variation of methane emission flux (seasonal coefficient of variation $=$ standard deviation/mean value of six growth stages, the coefficients of variation for TPE and TFE, respectively, were 0.396 and 0.383 in early rice, 1.414 and 1.327 in late rice). During the initial tillering stage of rice, the methane emission flux was kept at a relatively high level and was nearly the same as recorded in early rice. A peak of methane emission flux was observed during the full tillering stage of rice. Thereafter, with the growth and development of rice, methane emission 
$\square$ TPE ॠTFE سUPE 戸UFE
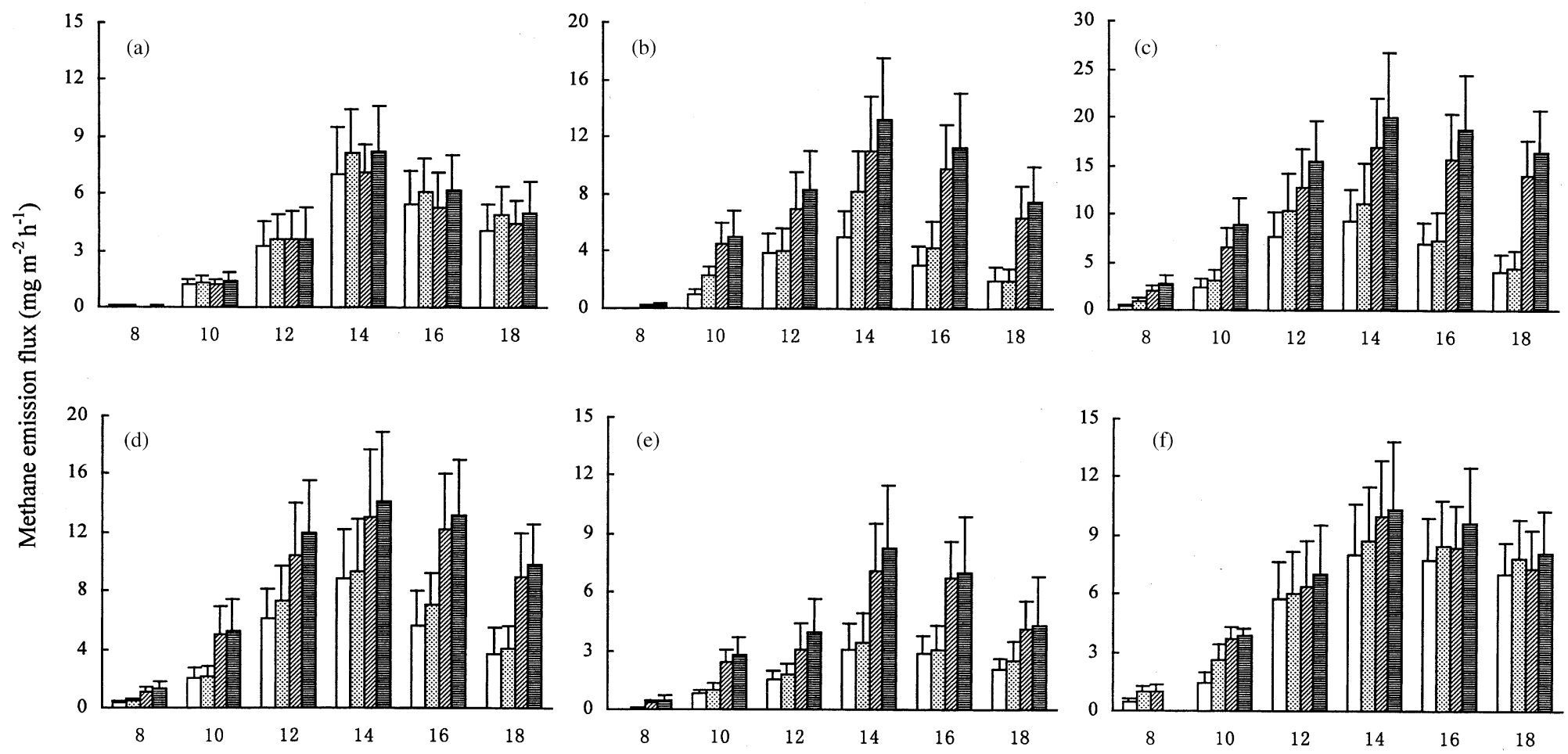

Sampling time (h)

Fig. 1. Diurnal variations in methane emission flux $\left(\mathrm{mg} \mathrm{m}^{-2} \mathrm{~h}^{-1}\right.$ ) during different growth stages of rice: (a) initial tillering stage; (b) full tillering stage; (c) young panicle differentiation stage; (d) booting stage; (e) complete heading stage; (f) ripening stage. TPE, rice-duck complex ecosystem in the plot experiment; TFE, rice-duck complex ecosystem in the field experiment; UPE, conventional rice field in the plot experiment; UFE, conventional rice field in the filed experiment. 

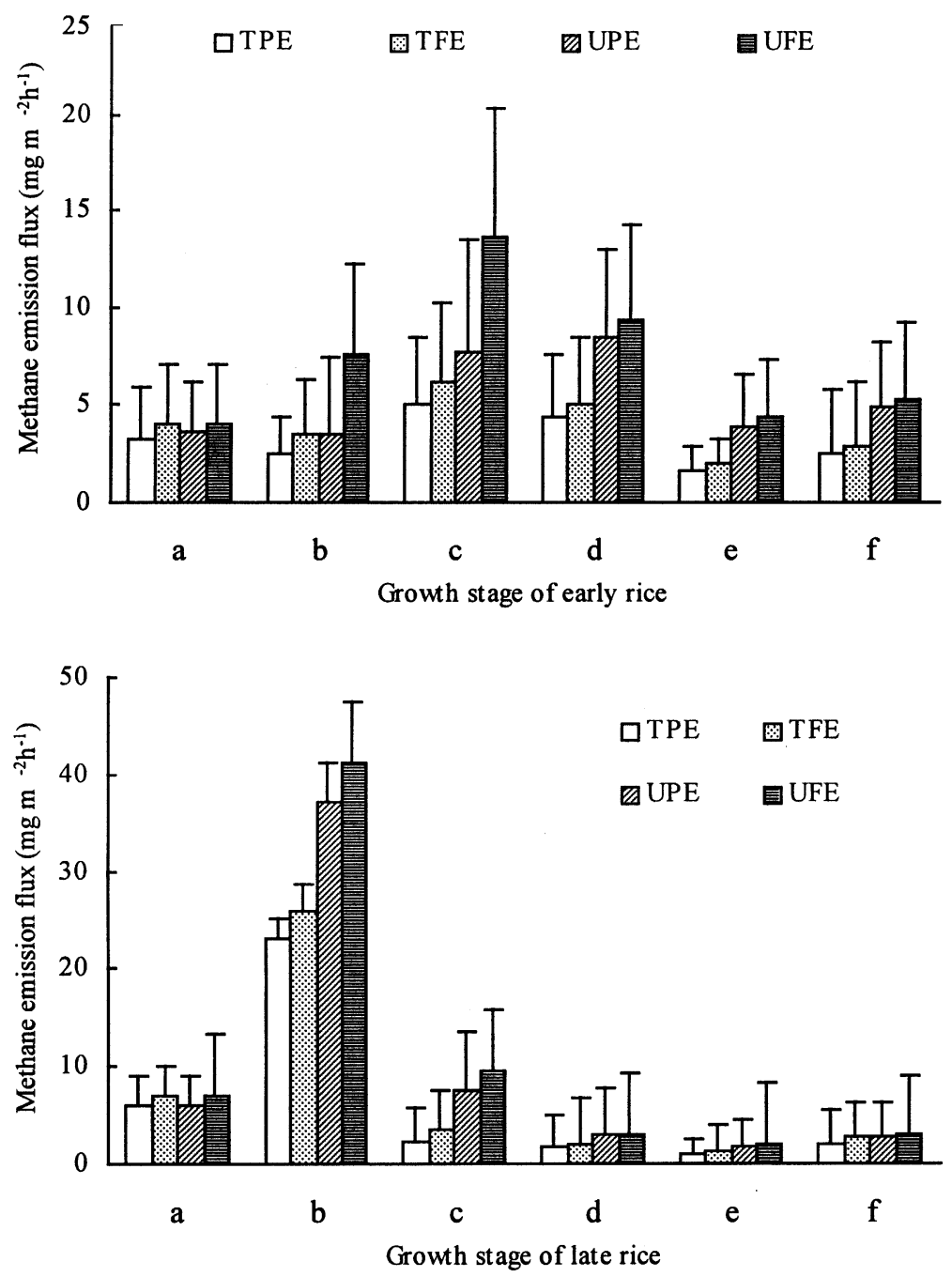

Fig. 2. Seasonal variations in methane emission flux $\left(\mathrm{mg} \mathrm{m}^{-2} \mathrm{~h}^{-1}\right)$ from paddy fields: (a) initial tillering stage; (b) full tillering stage; (c) young panicle differentiation stage; (d) booting stage; (e) complete heading stage; (f) ripening stage. TPE, rice-duck complex ecosystem in the plot experiment; TFE, rice-duck complex ecosystem in the field experiment; UPE, conventional rice field in the plot experiment; UFE, conventional rice field in the filed experiment.

flux decreased rapidly and dramatically. Particularly after the young panicle differentiation stage, the flux of methane emission maintained at an extremely low level all along. During the ripening stage of rice, as observed in early rice, methane emission flux increased slightly again. By calculation, the methane emission flux during the full tillering stage was 2.3-106.3 times higher than that during the other growth stages.

\section{Discussion}

Diurnal and seasonal variations in methane emission flux from rice fields have been found in literature (Wang, 1990; Adhya et al., 1994; Watanabe et al., 1995; Neue et al., 1997; Satpathy et al., 1997a; Kumaraswamy et al., 2000), but variation patterns were not completely consistent and this may be attributed to the different climatic status of experimen- 
tal localities and perhaps also to the experimental conditions.

The diurnal variation of methane emission flux could be mainly caused by variation in air temperature as well as in soil temperature within a day. The influences of soil temperature on diurnal variation in methane emission have been investigated in detail (Khan et al., 1997; Yang and Chang, 1997; Kumaraswamy et al., 2000; Cai et al., 1998; Wang et al., 1998, 2002). However, the air temperature effects on final methane emission are always negligible.

The methane production rate increases with soil temperature from 15 to $40^{\circ} \mathrm{C}$, and a significant correlation exists between methane production rate and soil temperature (Yang and Chang, 1997). As can be seen from Fig. 3, methane emission flux showed a clear diurnal relationship with soil temperature at $10 \mathrm{~cm}$ depth, which is in agreement with the findings reported by Khan et al. (1997) who found soil temperature to have a marked influence on methane emission and that the diurnal temperature effect on methane emission flux can be modeled with the Arrhenius equation. Different soil temperatures at different periods of time could bring on physiological and functional differences of rice plants such as $\mathrm{O}_{2}$ transportability, root exudation and root oxidation power of rice plants (Satpathy et al., 1997a; Kumaraswamy et al., 2000) and activities of methanogenic and methanotrophic populations in the rice rhizosphere (Adhya et al., 1994; Neue et al., 1997; Satpathy et al., 1997a). These physiological and functional differences may have a bearing on the methane-oxidizing capacity of rice rhizospheres (Satpathy et al., 1997a; Kumaraswamy et al., 2000), and then exert a substantial influence on the final methane emission.

Most of the methane, more than $96 \%$, produced in wetland rice soils escapes through the rice plants (Schutz et al., 1990; Wang, 1990; Wassmann et al., 1993). The dense root system of rice can also actively absorb soil moisture with dissolved methane, and then the dissolved methane can be transported into the aerating tissue of the rice plants, and at last be emitted to the atmosphere through rice plants via the respiration and transpiration of rice (Schutz et al., 1990; Wang, 1990). The air temperature has a profound impact on the respiration and transpiration of the plant, and consequently influences the final methane emission. Therefore, both air temperature as well as soil temperature can exercise crucial influence on the diurnal variation in methane emission flux. When the air temperature and the soil temperature vary little during cloudy and rainy days, the fluctuation of methane emission would not very significant under such weather conditions.

Duck possesses the characteristics of cold-resistance and hot-susceptibility, so duck always seeks for foods

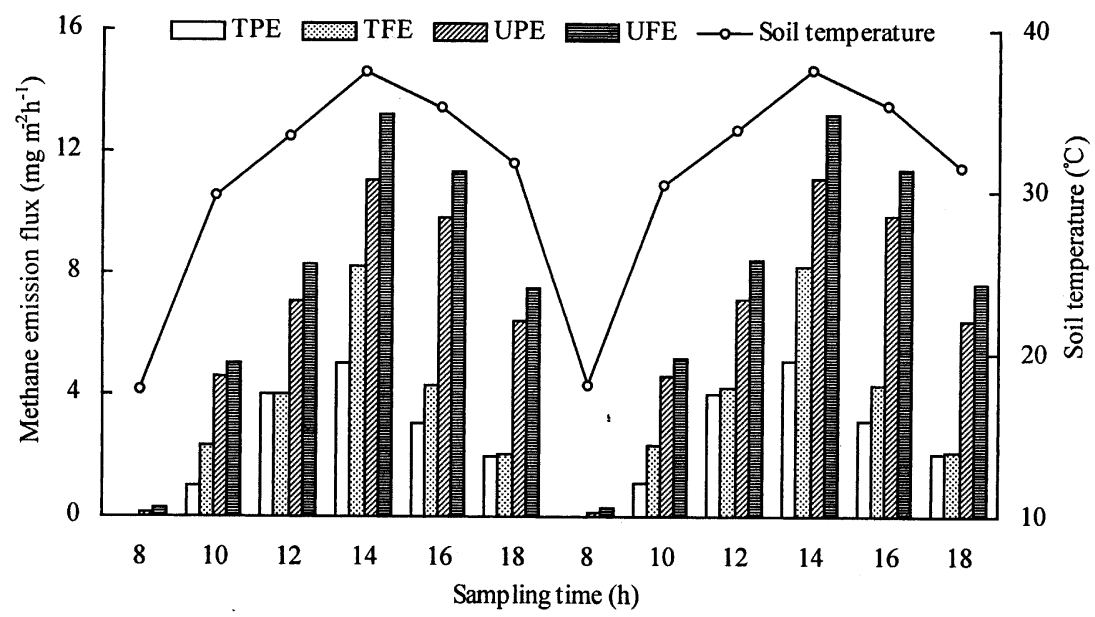

Fig. 3. Diurnal variations in methane emission flux $\left(\mathrm{mg} \mathrm{m}^{-2} \mathrm{~h}^{-1}\right)$ and soil temperature $(10 \mathrm{~cm}$ depth $)\left({ }^{\circ} \mathrm{C}\right)$ during the full tillering stage at 28 and 31 July 2001. TPE, rice-duck complex ecosystem in the plot experiment; TFE, rice-duck complex ecosystem in the field experiment; UPE, conventional rice field in the plot experiment; UFE, conventional rice field in the filed experiment. 
when the temperature is relatively low in the early morning and late afternoon (Wang, 2000; Wang et al., 2002). When the temperature is relatively high at noon, ducks always rest on the ridges of fields or their sheds, and their activities accordingly cut down (Wang, 2000; Wang et al., 2002). Because of the frequent activities of ducks, the dissolved oxygen concentration in the water body is greatly increased (Zheng et al., 1997; Wang, 2000), and thus methane produced in soil could be oxidized more quickly. At the same time, soil Eh value also accordingly increased, which inhibits the activities of methanogens (Zheng et al., 1997; Wang, 2000). Therefore, the amount of methane production decreased (Mishra et al., 1997; Shalini et al., 1997; Mohanty et al., 2001). So the different dissolved oxygen concentrations in the water body and the different soil Eh values caused by the different activity frequency of duck at different periods of time could be the main direct reasons for the different decrease rates of methane emission flux at different periods of time within a day.

Lower methane emission fluxes from PE than from FE could be explained by the following reasons. First, the plot area in PE is relatively small, and the scope of duck's activities in PE is also smaller than that in FE, and therefore, the influence of ducks' activities on methane production and emission is greater in PE than in FE. Second, because the rice fields in PE do not have a particularly high water-retaining capability, for the sake of maintaining a standing water depth of about $5 \mathrm{~cm}$, the number of irrigations in PE has to be increased. Thus the dissolved oxygen content in the water body and the soil redox potential are both enhanced (Wang et al., 2003), and as a consequence, the methane emission flux declined.

Final methane emission from paddy fields is an interactive effect of production, oxidation and transport to the atmosphere. The three processes are affected by biotic and abiotic factors such as the growth status of rice, air and soil temperature, soil characteristics (Conrad and Rothfuss, 1991; Masscheleyn et al., 1993; Neue, 1993; Sass et al., 1994; Yang et al., 1994; Hanson and Hanson, 1996; Yang and Chang, 1997, 1998; Rath et al., 1999; Kumaraswamy et al., 2000), and these affecting factors fluctuate markedly in different growth stages of rice, and so methane emission from rice fields presents seasonal variations (Watanabe et al., 1995; Satpathy et al., 1997a; Neue et al., 1997).
Furthermore, recent evidence also suggests that rhizosphere methane oxidation is growth stage-dependent (Kumaraswamy et al., 2000).

The seasonal variation in methane emission flux from RD may not be in agreement with the findings reported by some researchers (Holzapfel and Seiler, 1986a; Wang, 1990; Cai et al., 1998); however, it could be attributed mainly to the fact that our experiment was carried out under different conditions. Indeed, in previous investigations conventional rice fields had been used, whereas we used the rice fields with ducks reared in them.

Temperature is relatively low during the initial tillering stage of early rice, but the strong ferment of the submerged organic matter and organic manure provide abundant nutrient for methanogens (Neue and Sass, 1994), which stimulates their life activities and quicken the transformation from organic matter to methane, and so the methane emission flux during this stage is still kept at a relatively high level. During the full tillering stage of early rice, temperature begins to rise, and the aerating tissue of rice plants is also relatively developed, but the methane emission flux was slightly lower than that during the initial tillering stage and the reason for this is unknown, which is also inconsistent with the findings reported by Cai et al. (1998) who found methane emission flux to remain at a relatively high level all long from the beginning of transplanting to 50-60 days after transplanting. The peak of methane emission flux from early rice appeared in the young panicle differentiation stage, but not in the early growth stages (commonly in the tillering stage) as recorded by Holzapfel and Seiler (1986a) and Wang et al. (2002), and this may be due to a low soil temperature in this stage and probably also to the poor conduction of methane from the bulk soil to the atmosphere (Singh et al., 1997; Wang et al., 1998).

In contrast, the seasonal variation pattern of methane emission from late rice is basically consistent with some research results (Holzapfel and Seiler, 1986a; Wang, 1990), but neither the appearance of the double-peak as recorded by Wang et al. (1998) and Wang et al. (2002), nor the maintenance of an extremely low emission level from the emission peak up to the harvesting as described by Cai et al. (1998) was observed.

The emergence of the methane emission flux peak is due mainly to the degradation of the available 
organic carbon in the form of root exudates and the strongly reducing conditions in the rice rhizosphere (Singh et al., 1997; Kumaraswamy et al., 2000). The decline in methane emission flux after the emission peak may be attributed to a low water-soluble carbon (Wang, 1990; Kumaraswamy et al., 2000; Wang et al., 2002). During the ripening stage, methane emission flux increased to a varying degree, which is in accordance with other findings reported by some researchers (Kludze et al., 1996; Singh et al., 1997; Wang et al., 1998). Wang et al. (1998) suggest that the release of a part of methane absorbed by soil porosity upon drainage of water from rice fields during the ripening stage is the main reason for the increase in methane emission flux. But as far as the RD is concerned, because of feeding activities of ducks day and night in paddy fields, the amount of methane absorbed by soil porosity should be very small. Therefore, the climb in methane emission flux during this stage could be attributed primarily to the availability of additional organic matter for methanogenic bacteria in the form of sloughed off root cap cells and dead microbial material (Raimbault et al., 1997).

The soil temperature is higher during the late rice than during the early rice, and a relatively high temperature is more favorable for the growth and development of methanogens, whose optimum growth temperature is approximately $40^{\circ} \mathrm{C}$ (Wang et al., 1998). In addition, the activity frequency of duck also decreases under a high-temperature condition (Wang, 2000; Wang et al., 2002), and accordingly the influence of duck on methane production and emission weakens. Therefore, the total amount of methane emission from late rice was higher than that from early rice (Table 5).
Wetland rice fields are considered to be a major biogenic source of methane emission (Masscheleyn et al., 1993; Neue, 1993; Sass et al., 1994; Yang et al., 1994; Hanson and Hanson, 1996; Singh et al., 1997; Yang and Chang, 1997; Rath et al., 1999; Kumaraswamy et al., 2000). In the course of the methane production and emission, the environmental condition of rice growth is a determinative factor, and rice plants also play an important role in the emission of methane to the atmosphere by acting as a conduit for the transfer of methane from soil to the atmosphere (Singh et al., 1997; Reiner and Milkha, 2000; Wassmann and Milkha, 2000). Approximately $80-90 \%$ of the methane produced in soil is oxidized by methane-oxidizing bacteria before emitting into the atmosphere (Conrad and Rothfuss, 1991; Kumaraswamy et al., 2000; Wassmann and Milkha, 2000). Therefore, the impacts of the status and the environmental conditions of rice plant growth on methane production and emission are very profound. In rice-duck complex ecosystem, a significant reduction in methane emission from paddy fields may be explained in the following ways.

First, because ducks can consume weeds, planktons and other aerobic organisms in paddy fields (Table 2), the dissolved oxygen consumption in water body by weeds and aerobic organisms is lessened, and the dissolved oxygen content in water body accordingly increased, which brings on the amount of methane oxidization an increase and the methane production a decrease, consequently the final methane emission dropped; at the same time, the elimination of aquatic weeds, especially grasses, are unfavorable for the methane emission, because they act as transporter of methane formed in submerged soil, although at a

Table 5

Amount of methane emission $\left(\mathrm{g} \mathrm{m}^{-2}\right)$ during different growth stages of rice (PE)

\begin{tabular}{|c|c|c|c|c|c|c|c|c|}
\hline & & $\mathrm{IT}^{\mathrm{a}}$ & $\mathrm{FT}^{\mathrm{a}}$ & $\mathrm{YPD}^{\mathrm{a}}$ & $\mathrm{BO}^{\mathrm{a}}$ & $\mathrm{CH}^{\mathrm{a}}$ & $\mathrm{RI}^{\mathrm{a}}$ & Total \\
\hline Early rice & $\begin{array}{l}\mathrm{TPE}^{\mathrm{b}} \\
\mathrm{UPE}^{\mathrm{b}}\end{array}$ & $\begin{array}{l}1.420 \mathrm{~A}^{\mathrm{c}} \\
1.420 \mathrm{~A}\end{array}$ & $\begin{array}{l}0.639 \mathrm{~A} \\
1.243 \mathrm{~B}\end{array}$ & $\begin{array}{l}1.496 \mathrm{~A} \\
3.064 \mathrm{~B}\end{array}$ & $\begin{array}{l}0.819 \mathrm{~A} \\
2.180 \mathrm{~B}\end{array}$ & $\begin{array}{l}0.319 \mathrm{~A} \\
0.892 \mathrm{~B}\end{array}$ & $\begin{array}{l}0.924 \mathrm{~A} \\
1.092 \mathrm{~A}\end{array}$ & $\begin{array}{l}5.617 \mathrm{~A} \\
9.891 \mathrm{~B}\end{array}$ \\
\hline Late rice & $\begin{array}{l}\text { TPE } \\
\text { UPE }\end{array}$ & $\begin{array}{l}2.766 \mathrm{~A} \\
2.776 \mathrm{~A}\end{array}$ & $\begin{array}{l}5.075 \mathrm{~A} \\
8.877 \mathrm{~B}\end{array}$ & $\begin{array}{l}1.419 \mathrm{~A} \\
3.727 \mathrm{~B}\end{array}$ & $\begin{array}{l}0.224 \text { A } \\
0.702 \text { B }\end{array}$ & $\begin{array}{l}0.181 \text { A } \\
0.447 \text { B }\end{array}$ & $\begin{array}{l}0.438 \mathrm{~A} \\
0.525 \mathrm{~A}\end{array}$ & $\begin{array}{l}10.103 \mathrm{~A} \\
17.054 \mathrm{~B}\end{array}$ \\
\hline
\end{tabular}

${ }^{\text {a }}$ IT, initial tillering stage; FT, full tillering stage; YPD, young panicle differentiation stage; $\mathrm{BO}$, booting stage; $\mathrm{CH}$, complete heading stage; RI, ripening stage.

${ }^{\mathrm{b}}$ TPE, rice-duck complex ecosystem in the plot experiment; UPE, conventional rice field in the plot experiment.

${ }^{c}$ Values in the same columns that do not contain the same letters are significantly different at the $1 \%$ level. 
much slower rate (Holzapfel et al., 1986b; Mohanty et al., 2001). Second, ducks often inhabit the open field, and their activities such as feeding harrow the soil, quicken the gas exchange between the soil and the atmosphere, increase the contact opportunity of soil with oxygen, ameliorate the soil redox status (Wang et al., 2003), and thus reduce the amount of methane emission (Mishra et al., 1997; Shalini et al., 1997; Mohanty et al., 2001). Third, the feeding activities of ducks decrease the number of weeds and unproductive tillers of rice (Table 2), and accordingly reduce the amount of methane production resulting from their decay and decomposition under strictly anaerobic conditions. Fourth, no application of pesticides and herbicides throughout the growth period of rice maybe exercises a positive influence on mitigation in methane emission from rice-duck complex ecosystem (Topp, 1993; Kumaraswamy et al., 1997, 1998, 2000; Satpathy et al., 1997b; Boeckx et al., 1998). So far, however, there is no an inconclusive result about the effects of pesticides and herbicides on bacteria involved in the production or consumption of $\mathrm{CH}_{4}$, and the reason for their inhibition or stimulation effect on methane emission is also unknown (Kumaraswamy et al., 2000). Finally, paddy fields with a standing water depth of about $5 \mathrm{~cm}$ during the period of raising duck emit less methane, in spite of a higher rate of production, which is attributed to the decreased transport and release of methane due to the submergence of aerial parts of the rice plants (Neue, 1993; Kumaraswamy et al., 2000).

\section{Conclusions}

The role of ducks in the regulation of methane emission comprises many aspects involving virtually every level of the methane budget in rice fields. A rice-duck complex ecological planting and breeding model is also required to be ecologically and economically acceptable and sustainable. This study clearly indicates the possibility of reducing methane emission under this complex ecosystem. Coupled with its relatively high economic benefits and preferable ecological benefits, wetland rice-duck complex ecological model could be a desirable integrated utilization method of paddy fields, and also embodies the principles and concepts of sustainable agricultural systems proposed recently throughout the world. This planting and breeding model could also potentially play an important role in accelerating current agricultural development and in advancing the current adjustment to the structure of agriculture in China, especially in preventing and controlling its contribution to the global climatic warming. But our current findings about this model are still insufficient for its large-scale extension, and further research is warranted in order to fully understand the mechanism of this model for mitigation in methane emission, particularly with respect to the interactive relationships among the mechanisms involved.

\section{Acknowledgements}

This research was a part of the National Nature Science Foundation of China (No. 39670142) and 863-funded project of China (No. 863-306-ZD05-3-E). We thank Dr. A. Linda and two anonymous reviewers for their suggestions and comments in improving the manuscript.

\section{References}

Adhya, T.K., Rath, A.K., Gupta, P.K., Rao, P.R., Das, S.N., Parida, K.M., Parasher, D.C., Sethunathan, N., 1994. Methane emission from flooded rice fields under irrigated conditions. Biol. Fert. Soils 18, 245-248.

Anastasi, C., Dowding, M., Simpson, V.J., 1992. Future $\mathrm{CH}_{4}$ emission from rice production. J. Geophys. Res. 97, 7521-7525.

Boeckx, P., Cleemput, O.V., Meyer, T., 1998. The influence of land use and pesticides on methane oxidation in some Belgian soils. Biol. Fert. Soils 27, 293-298.

Cai, Z.C., Shen, G.Y., Yan, X.Y., 1998. Effects of soil texture, soil temperature and $\mathrm{Eh}$ on methane emission from rice paddy fields. Acta Pedologica Sinica 35 (2), 145-154.

Conrad, R., Rothfuss, F., 1991. Methane oxidation in the soil surface layer of a flooded rice field and the effect of ammonium. Biol. Fert. Soils 12, 28-32.

Conrad, R., 1996. Soil microorganisms as controllers of atmospheric trace gases, $\left(\mathrm{H}_{2}, \mathrm{CO}, \mathrm{CH}_{4}, \mathrm{OCS}, \mathrm{N}_{2} \mathrm{O}\right.$ and $\left.\mathrm{NO}\right)$. Microbiol. Rev. 60, 609-640.

Denier, V.D., Gon, H.A.C., Neue, H.U., 1996. Oxidation of methane in the rhizosphere of rice plants. Biol. Fert. Soils 22, 359-366.

Ekurem, E., Ryohei, Y., 1996. Comparative studies on behavior, weeding and pest control of duck free ranged in paddy fields. Jpn. Poult. Sci. 33, 261-267.

Hanson, R.S., Hanson, T.E., 1996. Methanotrophic bacteria. Microbiol. Rev. 60, 439-471. 
Hogan, K.B., Hoffman, J.S., Thompson, A.M., 1991. Methane on the greenhouse agenda. Nature 354, 181-182.

Holzapfel, P.A., Seiler, W., 1986a. Methane emission during the cultivation period from an Italian rice paddy. J. Geophys. Res. 91, 11803-11814.

Holzapfel, P.A., Conrad, R., Seiler, W., 1986b. Effects of vegetation on the emission of methane from submerged paddy soil. Plant Soil 92, 223-233.

Khan, R.Z., Miiller, C., Sommer, S.G., 1997. Micrometeorological mass balance technique for measuring $\mathrm{CH}_{4}$ emission from stored cattle slurry. Biol. Fert. Soils 24, 442-444.

Kludze, H.K., Neue, H.U., Llenaresas, D., Lantin, R.S., 1996. Rice root exudation and its impact on methane. production. In: Proceedings of the International Symposium on Carbon Sequestration. Ohio State University, USA.

Kumaraswamy, S., Rath, A.K., Bharati, K., Ramakrishnan, B., Sethunathan, N., 1997. Influence of pesticide on methane oxidation in a flooded tropical rice soil. Bull. Environ. Contam. Toxicol. 59, 222-227.

Kumaraswamy, S., Rath, A.K., Satpathy, S.N., Ramakrishnan, B., Adhya, T.K., Sethunathan, N., 1998. Influence of an insecticide carbofuran on the production and oxidation of methane in a flooded rice soil. Biol. Fert. Soils 26, 362-366.

Kumaraswamy, S., Rath, A.K., Ramakrishnan, B., Sethunathan, N., 2000. Wetland rice soils as sources and sinks of methane: a review and prospects for research. Biol. Fert. Soils 31, 449-461.

Lin, K.F., Xiang, Y.L., Jiang, D.B., 2000. Studies on the amount of methane emission from paddy fields and its mitigation countermeasures. J. Agri-environ. Protect. 19 (5), 267-270.

Masscheleyn, P.H., Delaune, R.D., Patric, W.H., 1993. Methane and nitrous oxide emission from laboratory measurement of rice soil suspension: effect of soil oxidation reduction status. Chemosphere 26, 251-260.

Mishra, S., Rath, A.K., Adhya, T.K., Rao, V.R., 1997. Effect of continuous and alternate water regimes on methane efflux from rice under greenhouse conditions. Biol. Fert. Soils 24, 399-405.

Mohanty, S.R., Bharati, k., Moorthy, B.T.S., Ramakrishnan, R.V.R., Sethunathan, N., Adhya, T.K., 2001. Effect of the herbicide butachlor on methane emission and ebullition flux from a directseeded flooded rice field. Biol. Fert. Soils 33, 175-180.

Neue, H.U., 1993. Methane emission from rice fields. Bioscience $43,466-474$

Neue, H.U., Sass, R.L., 1994. Trace gas emission from rice fields. In: Prinn, P.G. (Ed.), Global Atmospheric-Biospheric Chemistry. Plenum Press, New York, USA, pp. 119-147.

Neue, H.U., Wassmann, R., Kludze, H.K., Bu, j., Lantin, R.S., 1997. Factors and processes controlling methane emission from rice fields. Nutr. Cycl. Agroecosys. 49, 111-117.

Parashar, D.C., Gupta, P.K., Rai, J., Sharma, R.C., Singh, N., 1993. Effect of soil temperature on methane emission from paddy field. Chemosphere 26, 247-250.

Raimbault, H., Rinaudo, G., Garcia, J.L., Boureau, M., 1997. A device to study metabolic gases in rice rhizosphere. Soil Biol. Biochem. 9, 193-196.

Rath, A.K., Mohanty, S.R., Mishra, S., Kumaraswamy, S., Ramakrishnan, B., Sethunathan, N., 1999. Methane production in unamended and rice-straw-amended soil at different moisture levels. Biol. Fert. Soils 28, 145-149.
Reiner, W., Milkha, S.A., 2000. The role of rice plants in regulating mechanisms of methane missions. Biol. Fert. Soils 31, 20-29.

Sass, R.L., Fisher, F.M., Harcombe, P.A., Tumer, F.T., 1990. Methane production and emission in a Texas rice field. Global Biogeochem. Cyc. 4, 47-68.

Sass, R.L., Fisher, F.M., Lewis, S.T., Jund, M.F., Turner, F.T., 1994. Methane emission from rice fields: effects of soil properties. Global Biogeochem. Cyc. 8, 135-140.

Satpathy, S.N., Rath, A.K., Ramakrishnan, B., Rao, V.R., Adhya, T.K., Sethunathan, N., 1997a. Diurnal variation in methane efflux at different stages of tropical rice. Plant Soil 195, 271276.

Satpathy, S.N., Rath, A.K., Mishra, S., Kumaraswamy, S., Ramakrishnan, B., Adhya, T.K., Sethunathan, N., 1997b. Effect of hexachlorocyclohexane on methane production and emission from flooded rice soils. Chemosphere 34, 2663-2671.

Schutz, H., Seiler, W., Conrad, R., 1990. Influence of soil temperature on methane emission from rice paddy fields. Biogeochemistry 11, 77-95.

Shalini, Si., Kumar, S., Jain, M.C., 1997. Methane emission from two Indian soils planted with different rice cultivars. Biol. Fert. Soils 25, 285-289.

Singh, J.S., Singh, S., 1995. Methanogenic bacteria, methanogenesis and methane emission from rice paddies. Trop. Ecol. 36, 145-165.

Singh, J.S., Singh, S., Raghubanshi, A.S., Singh, S., Kashyap, A.K., 1996. Methane flux from rice/wheat agroecosystem as affected by crop phenology, fertilization and water level. Plant Soil 183, 323-327.

Singh, S., Kumar, S., Jain, M.C., 1997. Methane emission from two Indian soils planted with different rice cultivars. Biol. Fert. Soils 25, 285-289.

Takai, Y., 1970. The mechanism of methane formation in flooded paddy soil. Soil Sci. Plant Nutr. 16, 238-244.

Topp, E., 1993. Effects of selected agrochemicals on methane oxidation by an organic agricultural soil. Can. J. Soil Sci. 73, 287-291.

Wang, H., Huang, H., 2002. Analysis on ecological and economic benefits of complex ecosystem in wetland paddy fields. Chin. Agric. Sci. Bull. 18 (1), 71-75.

Wang, H., Huang, H., Yang, Z.H., Liao, X.L., 2003. Studies on integrated benefits of wetland rice-duck complex ecosystem. Rural Eco-Environ. 3, 45-48.

Wang, L., Wei, C.F., Xie, D.T., 2002. Research advances on methane emission from rice paddy. Soil Environ. Sci. 11 (2), $158-162$

Wang, M.X., 1990. Methane emission from a Chinese rice paddy fields. Acta Meteorologica Sinica 4, 265-274.

Wang, M.X., Li, J., Zheng, X.H., 1998. Methane emission and mechanisms of methane production, oxidation, transportation in the rice fields. Scientia Atmospheric Sinica 22 (4), 600-612.

Wang, Y., 2000. Studies on ecological benefits of planting and breeding model in rice fields. Acta Ecologica Sinica 20 (2), 311-316.

Wassmann, R., Papen, H., Rennenberg, H., 1993. Methane emission from rice paddies and possible mitigation options. Chemosphere 26, 201-217. 
Wassmann, R., Milkha, S.A., 2000. The role of rice plants in regulating mechanisms of methane missions. Biol. Fert. Soils $31,20-29$.

Watanabe, A., Kajiwara, M., Tashiro, T., Kimura, M., 1995. Influence of rice cultivar on methane emission from paddy fields. Plant Soil 176, 51-56.

Watanabe, I., Hashimoto, T., Shimoyama, A., 1997. Methaneoxidizing activities and methanotrophic populations associated with wetland rice plants. Biol. Fert. Soils 24, 261265 .

Wei, C.F., 2000. The effects of cultivation system on methane emission from winter flooded paddy fields in southwest area. Acta Pedologica Sinica 37 (2), 157-164.
Yang, S.S., Lin, C.C., Chang, E.H., Chang, R.S., Hung, S.N., 1994. Effect of fertilizer, soil type, growth season on methane production and emission in the paddy soils of Taiwan. J. Biomass Energy Soc. China 13, 68-87.

Yang, S.S., Chang, E.H., 1997. Effect of fertilizer application on methane emission/production in the paddy soils of Taiwan. Biol. Fert. Soils 25, 245-251.

Yang, S.S., Chang, E.H., 1998. Effect of environmental conditions on methane production and emission from paddy soil. Agric. Ecosyst. Environ. 69, 69-80.

Zheng, Y.H., Deng, G.B., Lu, G.M., 1997. Eco-economic benefits of rice-fish-duck complex ecosystem. J. Appl. Ecol. 8 (4), 431-434. 